\title{
Exercise and pregnancy in recreational and elite athletes: 2016/17 evidence summary from the IOC Expert Group Meeting, Lausanne. Part 3-exercise in the postpartum period
}

\author{
Kari Bø, ${ }^{1}$ Raul Artal, ${ }^{2}$ Ruben Barakat, ${ }^{3}$ Wendy J Brown, ${ }^{4}$ Gregory A L Davies, ${ }^{5}$ \\ Michael Dooley, ${ }^{6,7}$ Kelly R Evenson, ${ }^{8}$ Lene A H Haakstad, ${ }^{1}$ Bengt Kayser, ${ }^{9}$ \\ Tarja I Kinnunen, ${ }^{10}$ Karin Larsén, ${ }^{11}$ Michelle F Mottola, ${ }^{12}$ Ingrid Nygaard, ${ }^{13}$ \\ Mireille van Poppel, ${ }^{14}$ Britt Stuge, ${ }^{15}$ Karim M Khan, ${ }^{16}$ IOC Medical Commission ${ }^{17}$
}

For numbered affiliations see end of article.

\section{Correspondence to}

Professor Kari Bø, Department of Sport Medicine, Norwegian School of Sport Sciences, Oslo 0806, Norway; kari.bo@nih.no

Accepted 23 April 2017

To cite: Bø K, Artal R, Barakat $\mathrm{R}$, et al. Br I Sports Med Published Online First: [please include Day Month Year].doi:10.1136/ bjsports-2017-097964

\section{BACKGROUND}

This is Part 3 in the series of reviews from the IOC expert committee on exercise and pregnancy in recreational and elite athletes. Part 1 focused on the effects of training during pregnancy and on the management of common pregnancy-related complaints experienced by athletes ${ }^{1}$; Part 2 addressed maternal and fetal perinatal outcomes. ${ }^{2}$ In this part, we review the implications of pregnancy and childbirth on return to exercise and on common illnesses and complaints in the postpartum period.

The postpartum period can be divided into hospital-based (during hospital stay), immediate postpartum (hospital discharge to 6 weeks postpartum) and later postpartum (6 weeks to 1 year, corresponding sometimes to cessation of breast feeding). ${ }^{3}$ In the literature, the postpartum period is usually defined as the first 6 weeks after pregnancy, during which time women have not typically been encouraged to exercise, except for strength training of the pelvic floor muscles. However, 6 weeks is an arbitrary time point and, anecdotally, many elite athletes report starting exercise inside that period. For the purpose of the present review, we consider the postpartum period to be up to 12 months following birth.

\section{AIMS}

The aims of this paper are to present (1) the findings from a systematic review of the scientific literature on factors related to returning to exercise after childbirth in recreational and elite athletes, and (2) the prevalence, risk factors and evidence for prevention and treatment of common postpartum conditions that may affect sport performance and overall quality of life.

\section{METHODS}

For each section of the document, a search strategy was performed using search terms such as 'pregnancy' OR 'pregnant' OR 'postpartum' AND 'exercise' OR 'physical activity' OR 'leisure activity' OR 'leisure' OR 'recreation' OR 'recreational activity' OR 'physical fitness' OR occupational activity' AND terms related to the condition under study (eg, 'pelvic girdle pain', 'urinary incontinence', 'weight retention'). All available databases were searched, with an emphasis on PubMed, Embase, Cochrane, PEDro, Web of Science and SPORTDiscus. In addition, existing postpartum physical activity guidelines with reference lists were scanned. The review of each topic followed the general order: prevalence of the condition in the general postpartum population, prevalence in high-level exercisers or elite athletes, risk factors in the general population and in relation to exercise and sport, and effect of preventive and treatment interventions for common conditions and complaints following pregnancy and childbirth. Level of evidence and grade of recommendations are reported for the common conditions and complaints only, and are according to the Cochrane Handbook (table 1), for prevention and treatment interventions.

Each member of the working group was assigned to be the lead author of one or more topics, and one to three others were assigned to review each topic. A first full consensus draft was reviewed before and during the 3-day IOC meeting (27-29 September 2015), and a new version of each topic was submitted to the meeting chairs (KB and KMK) shortly after the meeting. Each topic leader made amendments before sending a new version for comments to the working group.

\section{FACTORS RELATED TO RETURNING TO EXERCISE} AFTER CHILDBIRTH IN ELITE ATHLETES Pelvic floor injury and recovery after childbirth To date, scant research has been conducted regarding the regenerative capacity of the pelvic floor muscles following first-time vaginal delivery. ${ }^{4-6}$ However, early histological and proteomic markers of regeneration have been observed in the largest muscle of the pelvic floor, the levator ani muscle. ${ }^{45}$

Nerve injuries to the pelvic floor muscles during delivery have not been widely studied. In a longitudinal study of 96 first-time pregnant women, concentric needle electromyography tests showed partial denervation of the pelvic floor with consequent reinnervation in $80 \% .^{7}$ In another study of primiparous women, $30 \%$ demonstrated 


\begin{tabular}{ll}
\hline $\begin{array}{l}\text { Table } 1 \text { Levels of quality of a body of evidence in the GRADE } \\
\text { statement }\end{array}$ & Quality rating \\
\hline Underlying methodology & High \\
\hline $\begin{array}{l}\text { Randomised trials, or double-upgraded } \\
\text { observational studies }\end{array}$ & Moderate \\
$\begin{array}{l}\text { Downgraded randomised trials, or upgraded } \\
\text { observational studies }\end{array}$ & Low \\
$\begin{array}{l}\text { Double-downgraded randomised trials, or } \\
\text { observational studies }\end{array}$ & Very low \\
$\begin{array}{l}\text { Triple-downgraded randomised trials, or } \\
\text { downgraded observational studies or case series/ } \\
\text { case reports }\end{array}$ & \\
\hline
\end{tabular}

denervation of the levator ani muscle at 6 weeks postpartum. Only $35 \%$ recovered by 6 months. ${ }^{8}$

Changes in preparation for childbirth begin long before the onset of labour. The levator hiatus area begins to widen during pregnancy, increases significantly after vaginal birth, and in most women returns to an area similar to that seen after caesarean birth by 12 months postpartum. ${ }^{9}$ Recovery of the levator hiatus area, a reflection of recovery of the levator ani muscle and associated connective tissue and nerves, is generally maximised by 4-6 months postpartum. ${ }^{9} 10$ Bladder neck mobility increases after vaginal birth and, while the support to the bladder neck improves postpartum, mobility remains higher than when measured at 37 weeks' gestation. ${ }^{9} 11$

Postpartum MRI or ultrasound has shown that levator ani muscle defects resolve in some women between 6 weeks and 1 year. ${ }^{9}{ }^{12-15}$ It is unclear whether this represents actual repair, anatomic variation in muscle insertions or the technical limitations of the procedures. ${ }^{16}$

There are scant data about whether or not future pelvic floor health is impacted by resuming strenuous physical activity in the early postpartum period, during which muscles, nerves and connective tissue are actively recovering from vaginal birth. Early return to heavy physical work after childbirth increased the risks of urinary incontinence and pelvic organ prolapse in small populations of women in India ${ }^{17}$ and $\mathrm{Nepal}^{18}{ }^{18}$ respectively. We identified no studies on how the timing of return to strenuous exercise or competitive sport postpartum affects pelvic floor function in elite athletes. Theoretically, the pelvic floor muscles may be overloaded if they have not recovered completely before resuming strenuous exercise. It may be prudent for athletes whose delivery was complicated by a risk factor for levator ani muscle injury (anal sphincter tear, forceps delivery, long second stage, large baby) to minimise activities that generate large increases in intra-abdominal pressure and/or repetitive high impact for several months postpartum. However, we emphasise that there is no evidence to support this recommendation. There is an urgent need for more research on the effect of exercise postpartum on the pelvic floor.

\section{Returning to sport after operative delivery}

Women who undergo operative vaginal delivery (vacuum and forceps procedures) or caesarean section will have different recovery timelines than those who have had an uncomplicated vaginal birth. This may impact their desire and functional ability to return to exercise. The prevalence of levator avulsion is substantially higher after forceps compared with vacuum delivery. ${ }^{19-21}$ Compared with spontaneous vaginal delivery, forceps delivery, but not vacuum delivery, is associated with greater odds of pelvic organ prolapse and surgery for prolapse. ${ }^{20}$ There is conflicting information about the long-term impact of forceps versus vacuum delivery on urinary and faecal incontinence. ${ }^{22-25}$

Women who have undergone caesarean birth will experience more abdominal pain postpartum than those who have had vaginal birth. The Pfannenstiel incision, typically used for caesarean birth, is a horizontal incision about $3 \mathrm{~cm}$ above the symphysis pubis and typically $12-15 \mathrm{~cm}$ in length. The Pfannenstiel incision is not a muscle-cutting incision but rather splits the rectus abdominis muscles in the midline. The transversalis fascia is incised horizontally and during closure is usually closed with a running suture with a knot at either end of the incision. After caesarean birth, most women experience pain along the incision site requiring analgesia for 5-10 days. This pain is commonly worse in the corners of the incision where the body has begun reacting to the stitch material in the knots. Most, but not all, women will be physically recovered to begin training 4-6 weeks after surgery.

A multicentre follow-up study of 1507 primiparous women in Australia identified those who experienced caesarean section were more likely to report extreme tiredness at 6 (adjusted OR: $1.39 ; 95 \%$ CI 1.07 to 1.82 ) and 12 months postpartum (adjusted OR: $1.40 ; 95 \%$ CI 1.05 to 1.85 ), and were more likely to report back pain at 6 (adjusted OR: 1.37 ; 95\% CI 1.06 to 1.77 ) and 12 months postpartum (adjusted OR: $1.41 ; 95 \%$ CI 1.06 to 1.87 ). Women who had a caesarean section were less likely to report urinary incontinence at 3, 6 and 12 months postpartum, respectively (adjusted OR: 0.26 ; $95 \%$ CI 0.19 to 0.36 ; adjusted OR: 0.36 ; $95 \%$ CI 0.25 to 0.52 ; adjusted OR: 0.48 ; $95 \%$ CI 0.33 to 0.68 ). For all other physical health problems, the pattern of morbidity did not differ between caesarean section and spontaneous vaginal birth. ${ }^{26}$ After caesarean delivery, the uterine scar is initially about fivefold thicker on ultrasound but decreases gradually over 6 weeks. At 6 weeks, the scar thickness is still increased, suggesting that the process of uterine scar remodelling extends beyond this traditional postpartum period. ${ }^{27}$ We are not aware of any literature suggesting an association between physical activity and uterine scar dehiscence in non-pregnant women, regardless of whether the incision on the uterus is made horizontally or vertically.

The decision when to recommence exercise after caesarean section will be dependent on issues such as blood pressure, anaemia, fatigue, pain management and wound healing. Elite athletes who plan to regain their prepregnancy fitness levels should do this in collaboration with their obstetric care provider to ensure they are medically fit for exercise. Once medically cleared, women may participate in both aerobic and strength training starting gradually and increasing exercise time, frequency and intensity as tolerated by their body. Women need to be conscious of the fact that even a 15 -day to 30-day detraining period can lead to significant muscle atrophy, which will require reconditioning over time to replace. ${ }^{28}$ Given the recent abdominal surgery, women postcaesarean section must also be conscious of the time required for complete repair of the abdominal fascia, which regains $51 \%-59 \%$ of its original tensile strength 6 weeks postsurgery and by 6-7 months has only $73 \%-93 \%$ of its original tensile strength. ${ }^{29}$ Elite athletes returning to exercise postcaesarean section should reduce their level of exercise if they experience pain or other negative symptoms related to their surgery site.

\section{Physiological adaptations postpartum}

The substantial cardiovascular and respiratory adaptations of pregnancy were discussed in the first part of this series. ${ }^{1}$ After 
giving birth, in a non-athlete female population, one study suggested that it takes at least 2 months postpartum for the augmented cardiac response to exercise during pregnancy to subside. ${ }^{30}$ Another study found that, relative to prepregnancy values, fitness $\left(\mathrm{VO}_{2}=\mathrm{MAX}\right)$ and strength (1-RM) levels were decreased at 6 weeks postpartum, presumably as a consequence of reduced physical activity levels during pregnancy. ${ }^{31}$ Some of the loss was restored at 27 weeks postpartum. In one study of 13 healthy women, systemic vascular resistance remained decreased at 12 weeks postpartum compared with before conception. ${ }^{32}$

Longitudinal data from 15 nulliparous and 15 parous women, collected every 8 weeks during pregnancy, showed that resting heart rate peaked at term $15+/-1$ beat/min above prepregnancy levels $(57+/-1$ beat $/ \mathrm{min})$, while resting mean arterial pressure reached its low $(-6+/-1 \mathrm{~mm} \mathrm{Hg})$ at 16 weeks, returning to baseline at term. ${ }^{33}$ The increases in left ventricular volumes peaked and the decrease in peripheral resistance troughed at 24 weeks of gestation, and cardiac output peaked $(2.2+/-0.2 \mathrm{~L} /$ min) at 38 weeks. The magnitude was significantly greater during the second pregnancy than during the first. ${ }^{33}$ Postpartum measures at 12, 24 and 52 weeks showed that all cardiovascular measures (heart rate, arterial pressure, cardiac output, etc) gradually returned towards baseline, but remained significantly different from prepregnancy values at 1 year after both the first and second pregnancy. All respiratory parameters returned to prepregnancy values within 6-12 weeks postpartum.

One pregnancy training study was found on trained women among whom several were elite athletes. ${ }^{34}$ The general conclusion was that high fitness levels could be maintained or even increased during pregnancy with appropriate strenuous training regimens. No formal studies were found on elite athletes reporting the timing of return to prepregnancy training regimens and competition.

\section{Exercise and breast feeding}

The WHO advises women to breast feed for at least 6 months. ${ }^{35}$ In a study of long distance runners, many modified their running behaviour during breast feeding, but of those who ran competitively prior to pregnancy and breast fed, $84.1 \%$ reported running during breast feeding. ${ }^{36}$ Most felt that running had no effect on their ability to breast feed.

Pivarnik et al reviewed breast feeding in athletes, and found that the increased caloric expenditure associated with breast feeding impacts an athlete's postpartum weight loss and return to competition. ${ }^{37}$ The concern that intense exercise may impair milk production in quantity and nutritional qualities has not been confirmed. ${ }^{38} 39$ Instead, high-volume aerobic exercise during breast feeding resulted in slightly greater quality and quantity of milk. ${ }^{40}$ Moderate weight reduction while nursing is safe and does not compromise neonatal weight gain. ${ }^{41}$ Lactic acid concentration in breast milk increases after intense exercise. ${ }^{42}$ Further, as energy expenditure increases during physical activity, there is an increase in proinflammatory cytokines, but no change in immunoglobulin A. ${ }^{43}$

During pregnancy, if intestinal calcium is insufficient to meet the combined needs of the mother and the baby, there may be some bone resorption, which may be exacerbated by breast feeding. There is no evidence that this causes osteoporosis or fractures, as the maternal skeleton is restored to its prepregnancy mineral content and strength after weaning. To our knowledge there are no reports of pregnancy or lactation-related fractures in athletes, although 'excess exercise' is thought to be a risk factor for these rare conditions. ${ }^{44}$
At this time, data do not support a recommendation concerning exercise intensity and breast feeding. The Society of Obstetricians and Gynaecologists of Canada (SOGC) Clinical Practice Obstetrics Committee, the Executive and Council of SOGC, and the Board of Directors of the Canadian Society for Exercise Physiology guidelines state that women should be advised that moderate exercise during lactation does not affect the quantity or composition of breast milk or impact infant growth. ${ }^{45}$ In reviewing guidelines from different countries, Evenson $e t a l^{3}$ found that breast feeding was mentioned in the Australian, Norwegian and Canadian guidelines. ${ }^{3}$ In particular, the Australian guideline indicated that physical activity would not impact breast milk volume or composition or infant growth as long as the woman had appropriate food and fluid intake. The American College of Obstetricians and Gynecologists recommends that nursing women ensure adequate hydration before commencing exercise and that they consider feeding their infants before exercising to avoid the discomfort of engorged breasts during exercise. ${ }^{46}$

Athletes may benefit from wearing a personally fitted sports bra that offers support rather than compression, ${ }^{47} 48$ as this provides significantly increased breast and bra comfort compared with a standard encapsulation sport bra during exercise. ${ }^{49}$ Using a breast pump before exercise may allow the postpartum athlete greater flexibility in the workout and feeding schedule and should result in a more comfortable exercise experience if the breasts are not full. ${ }^{42}$

\section{Return to competitive sport}

There is scant knowledge on athletes returning to exercise and competition after childbirth. Beilock et al $l^{50}$ suggested that athletes may be able to alter their training patterns during pregnancy without a significant impact on their postpartum training programme. In a retrospective study of 40 Norwegian elite athletes, $77 \%$ continued to compete at the same level after childbirth. ${ }^{51}$ Within the first 6 weeks postpartum, 12 (38\%) of the elite athletes started jogging compared with 2 (4.3\%) in non-athletes. In a case study of a marathon runner, Potteiger et $^{\mathrm{n}} \mathrm{l}^{52}$ found that while the individual did not qualify for the Olympic marathon, she was able to resume an intense training regimen within 4 weeks after delivery with no apparent medical complications. In another study, female Olympic and masters athletes reported feeling more physically fit and having improved technical skill after childbirth and often improved the records they achieved before pregnancy. ${ }^{53}$

Since research concerning the exercise patterns of physically fit athletes during the postpartum period is limited, studies on physically fit soldiers can serve as a guide. The amount of time needed for postpartum soldiers to return to prepregnancy fitness condition, as evidenced by Army Physical Fitness Test scores, ranged from 2 to 24 months, with a mean of 11 months. ${ }^{54}$ Postpartum test scores were significantly affected by complications (postpartum thyroiditis, hypertension, haemorrhoids, mastitis and postpartum surgery), weight gain and breast feeding. Only $17 \%$ of the soldiers believed that 6 months is enough time to return to prepregnancy physical condition, while only $19 \%$ of the women performed at levels equal to or better on the 6-month test, compared with their prepregnancy test.

Postpartum resumption of physical activity is an individualised process. Given the scant data, there are no studies indicating that rapid resumption of activities is associated with adverse outcomes. However, because postpartum women have a degree of deconditioning, accepted wisdom is for gradual resumption of 
exercise. This phase clearly requires additional research. (Part 4 of this series will address research gaps.)

Elite athletes are likely to encounter the same physiological limitations during pregnancy as those faced by recreational athletes during pregnancy. ${ }^{37}$ Elite athletes tend to maintain a more strenuous training schedule throughout pregnancy and resume high-intensity postpartum training sooner. Based on the available data, prepregnancy exercise routines may be resumed gradually, as soon as it is physically and medically safe. This will vary from one individual to another and some women may resume an exercise routine within a few weeks of delivery. ${ }^{55}$ Women should discuss plans to resume exercise during the postpartum period with their physician to obtain individualised advice.

\section{COMMON POSTPARTUM COMPLAINTS AND DISEASES: RISK FACTORS, PREVENTION AND TREATMENT OPTIONS Postnatal depression}

The most common mental health problem in the postpartum period is postpartum or postnatal depression. ${ }^{56}$ This is defined as depression occurring within the 12 months after giving birth, and is experienced by approximately $20 \%$ of women. However, up to $50 \%$ of women experience high levels of depressive symptoms in this period. ${ }^{5657}$ Depressive symptoms typically include feelings of helplessness and hopelessness, sleep problems, decreased energy, decision-making difficulties, sad mood, loss of interest in activities, irritability, changes in eating patterns, restlessness and suicidal ideations or attempts. ${ }^{57}$ There is no specific information about the prevalence of postnatal depression in female athletes.

Postnatal depression is associated with lower quality of life in mothers and their babies, negative parenting behaviours, poorer mother-infant bonding, and physical and emotional problems. ${ }^{58-60}$ Women who experience postnatal depression also have twice the risk of suffering episodes of depression later in life. $^{61}$

\section{Prevention of postnatal depression}

In a review of associations between physical activity (either prepregnancy, during pregnancy or postpartum) and postnatal depressive symptoms, there was an inverse association in $7 / 7$ intervention studies and 6/10 observational studies. ${ }^{62}$ While noting the limited quality of many of these studies, the authors concluded that leisure time physical activity prior to, during and after pregnancy may be important for reducing the risk of postnatal depressive symptoms. ${ }^{62}$

The results of a large Norwegian randomised controlled trial (RCT) $(n=855)$ published after the above 2013 review concluded that a 12-week programme of aerobic and strength training during weeks 20-36 of pregnancy did not result in differences in the prevalence of high depressive symptoms in the intervention and control groups. ${ }^{63}$ Surprisingly, a subsample of the intervention group who had not exercised prior to pregnancy had reduced risk of postnatal depression at follow-up. ${ }^{63}$

Level of evidence: Low, no studies of athletes.

\section{Treatment of postnatal depression}

Treatment options for postnatal depression are the same as in other periods, and include the use of antidepressants and cognitive therapy. ${ }^{64}$ Although there are plausible mechanisms by which exercise may improve the symptoms of postnatal depression, a 2004 review of 21 non-biological or behavioural interventions for the treatment of postnatal depression found insufficient data from which to draw conclusions relating to exercise. ${ }^{65}$ In contrast, a 2007 review found two small RCTs that supported exercise as a useful treatment for women with postnatal depression. ${ }^{66}$ A further review and meta-analysis in 2009 included five RCTs or quasi-RCTs that compared any type of exercise intervention with other treatments in women with diagnosed postnatal depression. ${ }^{67}$ Three trials showed a significant difference and two did not. The effect of exercise (compared with no exercise) was small, there was considerable heterogeneity, and the overall difference was reduced and not significant when one study that included social support and exercise was excluded. The authors concluded that it was uncertain whether or not exercise reduces symptoms of postnatal depression, or whether or not the effects of exercise were confounded by the beneficial effects of social support. ${ }^{67}$ Further RCTs are required.

Level of evidence: Low, insufficient studies, none in athletes.

\section{Postpartum weight retention/loss \\ Background}

Average weight retention 1 year after pregnancy in the general population ranges from 0.5 to $4 \mathrm{~kg} .{ }^{68-70}$ Gaining more weight during pregnancy is consistently identified as the strongest predictor of excess postpartum weight retention. ${ }^{71}$ Excess weight retention postpartum is associated with increased longterm risk of obesity, cardiovascular disease and type 2 diabetes during midlife. ${ }^{6973}$ Both energy intake and energy expenditure (including energy expended through breast feeding) are associated with the rate of weight loss postpartum.

There are sparse data on postpartum weight loss in athletes. One small retrospective observational study of elite Norwegian athletes has shown that self-reported body mass index was lower at prepregnancy, at 6 weeks postpartum and at the time of completing the survey than in age-matched controls. ${ }^{51}$ At the time of completing the questionnaire, $81 \%$ of the athletes (mean: 6.5 years after birth) and 48\% of the controls (mean: 8.5 years after birth) had returned to their prepregnancy weight.

\section{Role of physical activity in postpartum weight loss}

Most of the systematic reviews in this area included studies that evaluated the role of physical activity, either alone or in combination with a dietary intervention, on postpartum weight retention or weight loss. All of the included studies were with population samples (ie, non-athletes), and most physical activity interventions aimed to encourage the women to achieve recommended levels of physical activity for health benefits (ie, $\geq 150 \mathrm{~min}$ per week of at least moderate-intensity activity). This is much less than that typically reported by elite athletes and results differed between studies. ${ }^{69} 71$ 74-77 We identified only one small intervention study with athletes. Kardel compared the effects of two training interventions on gestational weight gain and postpartum weight. ${ }^{34}$ Both groups had the same intensity of muscle strength training, aerobic interval training and aerobic endurance training in their programmes, but the high-volume exercise group $(n=20)$ had more of each type of training than the medium-volume exercise group $(n=21)$. There was no non-exercising control group, and the athletes selected their preferred programme. There were no differences in body weight between the groups at 6 or 12 weeks postpartum. The mean weight was $72.2 \mathrm{~kg}$ in both groups at 38 weeks' gestation. At 6 weeks postpartum the high-volume exercise group weighed slightly less than the medium exercise group, but the mean weight at 12 weeks postpartum was very similar (63.2 and $63.0 \mathrm{~kg}$, respectively). 
Level of evidence: Low, insufficient studies in the general exercising population and in elite athletes.

\section{MUSCULOSKELETAL COMPLAINTS Low back and pelvic girdle pain}

Although the majority of women with low back pain and pelvic girdle pain recover spontaneously soon after delivery, about $20 \%$ report persistent pain for years. ${ }^{78}$ A large longitudinal population-based study found that $22 \%$ of women with pelvic girdle pain in pregnancy reported persistent pelvic girdle pain 6 months after delivery. ${ }^{79}$ Of these, $16 \%$ reported severe complaints. The recovery rates were high, but decreased with increasing levels of pain severity in pregnancy. ${ }^{80}$ Caesarean delivery increased the risk for persistent severe pelvic girdle pain 6 months postpartum. ${ }^{80}$ In the only study among elite athletes, $12.6 \%$ reported retrospectively that they experienced pelvic girdle pain 6 weeks postpartum and 9.7\% experienced low back pain. ${ }^{51}$ The prevalence increased to $19.4 \%$ for pelvic girdle pain and $29.0 \%$ for low back pain from 6 weeks postpartum to the time of completing the questionnaire $0-17$ years after delivery.

\section{Prevention and treatment}

Four RCTs of high methodological quality have investigated the effectiveness of different exercise programmes of low back pain and pelvic girdle pain in the general postpartum population. ${ }^{81-84}$ Only one of these RCTs demonstrated statistically and clinically significant positive and long-lasting effects of specific exercises in combination with individual physiotherapy on functional status, pain and physical health (SF-36). ${ }^{84} 85$ Disability was reduced by more than $50 \%$ for the exercise group compared with negligible changes in the control group. The main focus of the exercises (which was on the dynamic control of a neutral position of the lumbopelvis, ergonomic advice and development of strength and endurance to manage the physical demands facing each individual) was to improve coordination of the local and overall muscle system. The women were asked to perform their 30-60 min exercise programme 3 days per week and they adhered closely to this individually designed programme for 20 weeks. Compared with the other three studies, the study by Stuge et al differed in many aspects, such as individual guidance of a specialised women's health physiotherapist, dosage, and type and duration of exercises. ${ }^{86}$ No studies examining a treatment programme for low back pain or pelvic girdle pain in elite athletes were found. In the last decade, core stabilisation exercises have grown in popularity. ${ }^{87}$ However, a recent systematic review showed strong evidence that stabilisation exercises generally are not more effective than any other form of active exercise in the long term. ${ }^{88}$ A condition-specific outcome measure, the Pelvic Girdle Questionnaire, is reliable, valid and developed for pregnant and non-pregnant women with pelvic girdle pain for use in research and in clinical practice. ${ }^{89} 90$

Level of evidence: Moderate in the general postpartum population. No studies in elite athletes.

\section{Diastasis recti abdominis}

Postpartum prevalence rates of diastasis recti abdominis in the general population vary between $30 \%$ and $68 \% .^{91}{ }^{92}$ In a longitudinal study of 300 first-time pregnant women, prevalence rates were $33 \%$ at gestational week $21,60 \%$ at 6 weeks postdelivery, $45.4 \%$ at 6 months and $32.6 \%$ at 12 months postpartum. ${ }^{93}$ Diastasis recti abdominis is also common in middle-aged women with a prevalence of $52 \%$ among all questioned and $35 \%$ in nulliparous women, ${ }^{94}$ and may also be present in men. ${ }^{95}$ No studies were found on elite athletes postpartum.

Influence of diastasis recti abdominis on abdominal strength

In six women from gestational week 14 to 8 weeks postpartum, Gilleard and Brown found that women with inter-rectus distance $>3.5 \mathrm{~cm}$ measured with palpation had reduced curl-up capacity. ${ }^{96}$ This was supported by a study following 40 women postpartum, which found that postpartum women had weaker abdominal muscles than a control group. ${ }^{97}$ However, at 6 months postpartum there was no correlation between interrectus distance and reduced abdominal muscle strength.

\section{Diastasis and low back and pelvic girdle pain}

Parker et $a l^{98}$ found that women with diastasis recti abdominis had more abdominal and pelvic pain at 3 months postpartum than women without diastasis recti abdominis. ${ }^{98}$ However, two other studies found no differences in prevalence rates of low back pain or pelvic girdle pain in primiparous women 6 and 12 months postpartum with or without diastasis recti abdominis. ${ }^{93}$ ${ }^{99}$ No studies were found on elite athletes postpartum.

\section{Prevention and treatment}

While several web pages recommend different types of abdominal exercises to treat diastasis, there are no data to support these recommendations. A case-control study by Lo et al showed a protective effect of antepartum physical activity level. ${ }^{100}$ This was also the case in the study by Chiarello et al. ${ }^{101}$ In a systematic review by Benjamin et al, ${ }^{102}$ eight studies reported treating diastasis recti abdominis using abdominal exercises: four case studies, two retrospective observational studies, one quasi-experimental post-test study and one small RCT of a brief training intervention. ${ }^{103}$ This review concluded that non-specific exercise may or may not help to prevent or reduce diastasis recti abdominis during the antenatal or postnatal periods. An additional small RCT of only nine women, 3 months to 3 years postpartum, found a decline in diastasis recti abdominis in women doing a traditional abdominal exercise programme and women performing a core stability plank exercise, but no difference between the two groups. ${ }^{104}$

Given the limited research from very small studies of low methodological quality, there is no consensus on which abdominal exercises to recommend to correct diastasis recti abdominis postdelivery. ${ }^{99105}$ Recent research has questioned the use of the recommended in-drawing exercises (lifting the naval towards the spine, activating mainly the transversus abdominis and internal obliques) as these appear to widen, rather than narrow, the gap on ultrasound. ${ }^{105-107}$

There is little evidence for surgery to restore diastasis. Akram and Matzen identified 15 studies on surgical repair and found only one RCT, which compared the results of using two different sutures. ${ }^{108}$ The authors concluded that both groups had adequate correction of diastasis recti abdominis 6 months after surgery. This was supported by a recent RCT also comparing different sutures. ${ }^{109}$ No studies have been found on the prevention or treatment of diastasis recti abdominis in elite athletes.

Level of evidence: Insufficient evidence for the effect of either surgery or different exercise regimens on diastasis recti abdominis in the postpartum period. No studies on elite athletes.

\section{Pelvic floor disorders}

The main pelvic floor disorders postpartum are urinary incontinence, anal incontinence and pelvic organ prolapse. The 
prevalence of any type of urinary incontinence in primiparous women during the first year postpartum, regardless of delivery mode, is between $15 \%$ and $30 \% .{ }^{110}$ Johannessen et al found that one in five primiparous women suffered from anal incontinence 1 year after delivery. ${ }^{111}$ The main predictor for anal incontinence 1 year postpartum was anal incontinence in late pregnancy. Obstetric anal sphincter injury increased the risk of incontinence of stool and flatus (OR: 4.1; 95\% CI 1.7 to 9.6). Urgency of bowel evacuation was associated with older age and operative delivery. It is estimated that $>50 \%$ of women lose some pelvic support after vaginal delivery. ${ }^{112}$ At 3-6 months postpartum, prevalence rates of pelvic organ prolapse (stage II or higher in a scale of $0-4$ ) are between $18 \%$ and $56 \% .{ }^{113-115}$ Moreover, $15 \%-40 \%$ of primiparous women have a major defect of the levator ani muscle, and these women are twice as likely to have pelvic organ prolapse stage II or higher than those with an intact levator ani muscle. ${ }^{116}$

In a small retrospective questionnaire study on 40 elite athletes who had given birth (selected from Norwegian Olympic Committee and Confederation of Sport), the prevalence rate of stress urinary incontinence was $29 \%$ at 6 weeks postpartum and $35 \%$ at the time of completing the questionnaire. ${ }^{51}$ There were no differences in stress urinary incontinence prevalence between elite athletes and a matched control group of 80 women, with a measured mean of 7.5 years after delivery (range: 0-17 years).

\section{Prevention and treatment}

A Cochrane review concluded that postnatal women with persistent urinary incontinence 3 months after delivery and who received pelvic floor muscle training were about $40 \%$ less likely than women who did not receive treatment, or who received usual postnatal care, to report urinary incontinence 12 months after delivery (RR: $0.60,95 \%$ CI 0.35 to 1.03 , combined result of three trials). ${ }^{117}$ The more intensive the programme, the greater the treatment effect. ${ }^{117}$ However, the Cochrane review also concluded that 'the extent to which mixed prevention and treatment approaches to pelvic floor muscle training in the postnatal period are effective is less clear' (ie, offering advice on pelvic floor muscle training to all pregnant or postpartum women whether or not they have incontinence symptoms). Further, 'it is possible that mixed prevention and treatment approaches might be effective when the intervention is intensive enough'.

There is lack of evidence from RCTs on the effect of pelvic floor muscle training on anal incontinence postpartum. ${ }^{117}$ Several RCTs have found that pelvic floor muscle training can reduce pelvic organ prolapse stage and symptoms in middle-aged women, and it is recommended as first-line treatment (Durnea et al 2013). ${ }^{118}$ However, one RCT did not find any effect of pelvic floor muscle training starting 6 weeks postpartum on pelvic organ prolapse in primiparous women. ${ }^{119}$ Postpartum, the pelvic floor is weak and injured in most women, and women who did not train these muscles before birth may need instruction and supervision to be able to perform a correct pelvic floor muscle contraction. Women should start with contractions of short duration, with progression to holding periods of $6-8 \mathrm{~s}$ and continue to contract as close to maximum as possible with three sets of 8-12 contractions per day. ${ }^{117} 120$

A pessary, or a vaginal device placed into the vagina to support the pelvic organs, is also used to treat symptoms of pelvic floor disorders. Scant data suggest that in women with urinary incontinence, a pessary might be better than no treatment in reducing leakage. ${ }^{121}$ In women with pelvic organ prolapse, one randomised trial that compared two types of pessaries found reduction in symptoms in about $60 \%$ of women who completed the study. ${ }^{122}$ Whether a pessary might prevent pelvic floor symptoms, postpartum or at any other time has not been studied.

Level of evidence: Low for pelvic floor muscle training as prevention, but strong for pelvic floor muscle training as treatment of urinary incontinence in the general postpartum population. No studies on elite athletes. Low for pessary treatment of urinary incontinence or pelvic organ prolapse in the general population. No studies with postpartum women or elite athletes. Elite athletes with urinary incontinence or pelvic organ prolapse should be referred for pelvic floor muscle training and pessary use if necessary.

\section{Pelvic floor pain}

Pelvic floor pain is a specific subset of pelvic pain that consists of pain due specifically to the pelvic floor muscles, connective tissue or ligaments. Given this musculoskeletal aetiology, it is conceivable that highly active women might report different rates of pelvic floor pain than less physically active women. However, studying pelvic floor pain is difficult, as many different terms are used to express the finding of pelvic floor muscle pain and increased tension, including 'pelvic floor muscle pain syndrome', 'overactive pelvic floor', 'myofascial pelvic pain', 'levator tension myalgia' or 'hypertonic pelvic floor muscles'. Further compounding this difficulty is the fact that pain thought to be related to the pelvic floor is often due to other aetiologies. For example, in a prospective study of 114 female athletes with a suspected musculoskeletal aetiology for pelvic pain, who were referred to a surgical practice, $64.9 \%$ turned out to have injuries of the hip and/or soft tissue surrounding the hip. ${ }^{123}$ We identified no observational studies about pelvic floor pain in athletes.

\section{Prevention and treatment}

In a systematic review of 10 RCTs of pelvic floor muscle training for pelvic floor pain, Frawley concluded that to date there is scant evidence from high-quality RCTs to guide clinical practice in prevention and treatment of pelvic floor pain. ${ }^{124}$ Scant data suggest that, compared with saline injection, injection of botulinum toxin $\mathrm{A}$ into the pelvic floor muscles may decrease pain scores in non-athletes with chronic pelvic pain and 'evidence of pelvic floor muscle spasm'. ${ }^{125}$ We identified no RCTs about treatment of such pain in athletes.

Level of evidence: Low. No studies in elite athletes.

\section{Sexual dysfunction}

Sexual function is divided into four categories: pain, desire, arousal and orgasmic disorders. Disorders in each category are common, ${ }^{126}$ and diagnosing these disorders relies on self-report. A three-item screening questionnaire has been shown to be as effective as an interview with a psychologist in identifying sexual problems. ${ }^{127}$ About $90 \%$ of women are sexually active during pregnancy; this decreases to about $30 \%$ in the ninth month of pregnancy. ${ }^{128}$ Sexual desire generally decreases postpartum and improves over the course of the first postpartum year. ${ }^{129}$

About half of women who have a spontaneous vaginal delivery resume intercourse before 8 weeks postpartum ${ }^{130} 131$ Women with an intact perineum are more likely to resume vaginal intercourse earlier (by 6 weeks postpartum). ${ }^{132}$ However, the effect of perineal trauma on delaying intercourse is lost by 7-12 weeks postpartum. ${ }^{129}$ Women who breast feed are less likely to resume intercourse early in the postpartum period. ${ }^{133}$ 
Incidence of postpartum sexual dysfunction

Forty-one per cent to $83 \%$ of women report sexual dysfunction at 2-3 months postpartum. ${ }^{128134}$ Sexual pain is the most common cause of sexual dysfunction in the postpartum period. ${ }^{129}$ Of note, pain with intercourse may be present in up to one-quarter of women before pregnancy. ${ }^{135} 136$

\section{Risk factors for postpartum sexual dysfunction}

Risk factors for postpartum sexual dysfunction include infrequent sexual activity or delayed initiation of sexual activity (later than 9 weeks postpartum), being within the first 5 months after childbirth, primiparity, postpartum depression, treatment for depression and relationship dissatisfaction. ${ }^{128} 134$

The 2006 National Institutes of Health Consensus Conference on Maternal Demand Cesarean concluded that there was no high-quality evidence to show that either vaginal or caesarean birth resulted in better postpartum sexual function. ${ }^{137}$ In agreement with this, 6 years after first delivery, mode of delivery was not related to sexual function, with the exception that women who delivered by caesarean perceived that their vaginal tone was better. ${ }^{138}$ We identified no data on postpartum sexual dysfunction in female athletes and also no data on whether physical activity during or after delivery impacts sexual function in women.

\section{Treatment of postpartum sexual dysfunction}

In a systematic review that included 1341 women from eight RCTs, pelvic floor muscle training was found to improve at least one sexual variable in women with pelvic floor dysfunction. One study showed an improvement in postpartum women. ${ }^{139}$ Six years after first delivery, women who reported performing pelvic floor muscle training scored better on numerous sexual function questions than women who did not report this. ${ }^{138}$

Treatment is generally based on anecdotal evidence and includes, most importantly, addressing sexual function as a serious concern, reviewing the importance of adequate rest and time for intimacy, and encouraging the use of vaginal lubricants. In women who report pain with intercourse, a careful examination of the vagina and vulva to assess healing is recommended.

Level of evidence: Low, no studies on elite athletes.

\section{SUMMARY}

This review found a limited number of studies on factors relating to return to exercise following pregnancy and childbirth in the general exercising population, and very few in elite athletes. There is also little information or evidence on which to base advice for athletes on issues relating to common complaints in the postpartum period. Both high-quality prospective cohort studies and RCTs are required. The former would be useful from a prevention viewpoint, in terms of understanding the determinants of common problems such as postnatal depression, weight retention and musculoskeletal complaints including pelvic floor disorders. More RCTs would shed light on the most effective treatment regimens for women with these problems, and would inform the advice given to athletes in terms of the optimal time to recommence training the cardiorespiratory and musculoskeletal systems.

Given the challenges of conducting studies with pregnant athletes, it would be helpful if researchers who are working on each of the main topics included in this chapter could agree on the same valid and reliable outcome measures, so that data can be pooled and treatments compared. Similarly, consensus is needed around how to assess physical activity to compare across studies. We agree with the thoughtful recommendations regarding return to sport from the First World Congress in Sports Physical Therapy 2016 Consensus statement, ${ }^{140}$ published after our own proceedings: Return to sport should be considered a continuum with three distinct elements: (1) return to participation, (2) return to sport and (3) return to performance. Within each element, the athlete, physician, physiotherapist and coach should carefully consider the unique elements of the athlete's personal performance, childbirth experience, lactation and sport demands to provide a flexible and individualised programme during recovery. ${ }^{140}$

\section{Author affiliations}

${ }^{1}$ Department of Sport Medicine, Norwegian School of Sport Sciences, Oslo, Norway

${ }^{2}$ Department of Obstetrics, Gynecology and Women's Health, Saint Louis University,

St Louis, Missouri, USA

${ }^{3}$ Facultad de Ciencias de la Actividad Física y del Deporte - INEF, Universidad Politécnica de Madrid, Madrid, Spain

${ }^{4}$ Centre for Research on Exercise Physical Activity and Health, School of Human Movement and Nutrition Sciences, University of Queensland, St Lucia, Australia

${ }^{5}$ Division of Maternal-Fetal Medicine, Department of Obstetrics and Gynecology, Queen's University, Kingston, Canada

${ }^{6}$ Department of Sport Gynaecology, Poundbury Clinic, Dorchester, UK

${ }^{7}$ Poundbury Clinic, King Edward VII Hospital, London, UK

${ }^{8}$ Department of Epidemiology, University of North Carolina at Chapel Hill, Chapel Hill, North Carolina, USA

${ }^{9}$ Faculty of Biology and Medicine, Institute of Sport Science, University of Lausanne,

Lausanne, Switzerland

${ }^{10}$ School of Health Sciences, University of Tampere, Tampere, Finland

${ }^{11}$ The Swedish School of Sport and Health Sciences, Stockholm, Sweden

${ }^{12} \mathrm{R}$ Samuel McLaughlin Foundation-Exercise and Pregnancy Lab, The University of

Western Ontario, London, Canada

${ }^{13}$ Department of Obstetrics and Gynecology, University of Utah, Salt Lake City, Utah, USA

${ }^{14}$ Institute of Sport Science, University of Graz, Graz, Austria

${ }^{15}$ Division of Orthopaedic Surgery, Oslo University Hospital, Oslo, Norway

${ }^{16}$ Department of Family Practice and School of Kinesiology, Centre for Hip Health and Mobility, University of British Columbia, Vancouver, Canada

${ }^{17}$ IOC, Medical, Commission

Correction notice This paper has been amended since it was published Online First. Owing to a scripting error, some of the publisher names in the references were replaced with 'BMJ Publishing Group'. This only affected the full text version, not the PDF. We have since corrected these errors and the correct publishers have been inserted into the references.

Competing interests None declared.

Provenance and peer review Not commissioned; externally peer reviewed.

(c) Article author(s) (or their employer(s) unless otherwise stated in the text of the article) 2017. All rights reserved. No commercial use is permitted unless otherwise expressly granted.

\section{REFERENCES}

1 Bo K, Artal R, Barakat R, et al. Exercise and pregnancy in recreational and elite Athletes: 2016 evidence summary from the IOC expert group meeting, Lausanne. Part 1-exercise in women planning pregnancy and those who are pregnant. $\mathrm{Br} J$ Sports Med 2016;50:571-89.

2 Bo K, Artal R, Barakat R, et al. Exercise and pregnancy in recreational and elite Athletes: 2016 evidence summary from the IOC expert group meeting, Lausanne. Part 2-the effect of exercise on the fetus, labour and birth. Br J Sports Med 2016;50:1297-305.

3 Evenson KR, Mottola MF, Owe KM, et al. Summary of international guidelines for physical activity after pregnancy. Obstet Gyneco/ Surv 2014;69:407-14.

4 Cortes $\mathrm{E}$, te Fong LF, Hameed $\mathrm{M}$, et al. Insulin-like growth factor-1 gene splice variants as markers of muscle damage in levator ani muscle after the first vaginal delivery. Am J Obstet Gynecol 2005;193:64-70.

5 Dimpfl T, Jaeger C, Mueller-Felber W, et al. Myogenic changes of the levator ani muscle in premenopausal women: the impact of vaginal delivery and age. Neurourol Urodyn 1998; 17:197-205.

6 Bukovsky A, Copas P, Caudle MR, et al. Abnormal expression of p27kip1 protein in Levator ani muscle of aging women with pelvic floor disorders - a relationship to the cellular differentiation and degeneration. BMC Clin Pathol 2001;1:4.

7 Allen RE, Hosker GL, Smith AR, et al. Pelvic floor damage and childbirth: a neurophysiological study. Br J Obstet Gynaecol 1990;97:770-9.

8 South MM, Stinnett SS, Sanders DB, et al. Levator ani denervation and reinnervation 6 months after childbirth. Am J Obstet Gynecol 2009;200:e1-7:519.e1-519.e7. 
9 Stær-Jensen J, Siafarikas F, Hilde G, et al. Postpartum recovery of levator hiatus and bladder neck mobility in relation to pregnancy. Obstet Gynecol 2015;125:531-9.

10 Shek KL, Dietz HP. Intrapartum risk factors for levator trauma. BJOG 2010;117:1485-92.

11 Toozs-Hobson P, Balmforth J, Cardozo L, et al. The effect of mode of delivery on pelvic floor functional anatomy. Int Urogynecol J Pelvic Floor Dysfunct 2008;19:407-16.

12 Shek KL, Chantarasorn V, Langer S, et al. Does levator trauma 'heal'? Ultrasound Obstet Gynecol 2012;40:570-5.

13 Chan SS, Cheung RY, Yiu KW, et al. Effect of levator ani muscle injury on primiparous women during the first year after childbirth. Int Urogynecol J 2014;25:1381-8.

14 Branham V, Thomas J, Jaffe T, et al. Levator ani abnormality 6 weeks after delivery persists at 6 months. Am J Obstet Gynecol 2007;197:e-16:65.e1-65.e6.

15 van Delft KW, Thakar R, Sultan AH, et al. The natural history of levator avulsion one year following childbirth: a prospective study. BJOG 2015;122:1266-73.

16 Schwertner-Tiepelmann N, Thakar R, Sultan AH, et al. Obstetric levator ani muscle injuries: current status. Ultrasound Obstet Gynecol 2012;39:372-83.

17 Prabhu SA, Shanbhag SS. Prevalence and risk factors of urinary incontinence in women residing in a tribal area in Maharashtra, India. J Res Health Sci 2013:13:125-30.

18 Lien YS, Chen GD, Ng SC, Sc N. Prevalence of and risk factors for pelvic organ prolapse and lower urinary tract symptoms among women in rural Nepal. Int $J$ Gynaecol Obstet 2012;119:185-8.

19 Memon HU, Blomquist JL, Dietz HP, et al. Comparison of levator ani muscle avulsion injury after forceps-assisted and vacuum-assisted vaginal childbirth. Obstet Gynecol 2015;125:1080-7.

20 Volløyhaug I, Mørkved S, Salvesen Ø, et al. Forceps delivery is associated with increased risk of pelvic organ prolapse and muscle trauma: a crosssectional study 16-24 years after first delivery. Ultrasound Obstet Gynecol 2015:46:487-95.

21 Durnea CM, O'Reilly BA, Khashan AS, et al. Status of the pelvic floor in young primiparous women. Ultrasound Obstet Gynecol 2015;46:356-62.

22 Volløyhaug I, Mørkved S, Salvesen Ø, et al. Pelvic organ prolapse and incontinence 15-23 years after first delivery: a cross-sectional study. BJOG 2015;122:964-71.

23 Johanson RB, Heycock E, Carter J, et al. Maternal and child health after assisted vaginal delivery: five-year follow up of a randomised controlled study comparing forceps and ventouse. BJOG 2014;121 Suppl 7(Suppl 7):23-8.

24 Macarthur C, Wilson D, Herbison $\mathrm{P}$, et al. ProLong study group. Faecal incontinence persisting after childbirth: a 12 year longitudinal study. BJOG 2013;120:169-79. discussion 78-9.

25 O'Mahony F, Hofmeyr GJ, Menon V. Choice of instruments for assisted vaginal delivery. Cochrane Database Syst Rev 2010;11:Cd005455.

26 Woolhouse H, Perlen S, Gartland D, et al. Physical health and recovery in the first 18 months postpartum: does cesarean section reduce long-term morbidity? Birth 2012;39:221-9.

27 Hamar BD, Saber SB, Cackovic M, et al. Ultrasound evaluation of the uterine scar after cesarean delivery: a randomized controlled trial of one- and two-layer closure. Obstet Gynecol 2007;110:808-13.

28 Paddon-Jones D, Sheffield-Moore M, Cree MG, et al. Atrophy and impaired muscle protein synthesis during prolonged inactivity and stress. J Clin Endocrinol Metab 2006;91:4836-41.

29 Ceydeli A, Rucinski J, Wise L. Finding the best abdominal closure: an evidence-based review of the literature. Curr Surg 2005;62:220-5.

30 Sady MA, Haydon BB, Sady SP, et al. Cardiovascular response to maximal cycle exercise during pregnancy and at two and seven months post partum. Am J Obstet Gynecol 1990;162:1181-5.

31 Treuth MS, Butte NF, Puyau M. Pregnancy-related changes in physical activity, fitness, and strength. Med Sci Sports Exerc 2005;37:832-7.

32 Capeless EL, Clapp JF. When do cardiovascular parameters return to their preconception values? Am J Obstet Gynecol 1991;165(4 Pt 1):883-6.

33 Clapp JF, Capeless E. Cardiovascular function before, during, and after the first and subsequent pregnancies. Am J Cardiol 1997;80:1469-73.

34 Kardel KR. Effects of intense training during and after pregnancy in top-level Athletes. Scand J Med Sci Sports 2005;15:79-86.

35 WHO. Infant and young child feeding. Secondary infant and young child feeding. 2016; http://www.who.int/mediacentre/factsheets/fs342/en/.

36 Tenforde AS, Toth $\mathrm{KE}$, Langen $\mathrm{E}$, et al. Running habits of competitive runners during pregnancy and breastfeeding. Sports Health 2015;7:172-6.

37 Pivarnik JM, Perkins CD, Moyerbrailean T. Athletes and pregnancy. Clin Obstet Gynecol 2003;46:403-14.

38 Dewey KG. Effects of maternal caloric restriction and exercise during lactation. J Nutr 1998;128(2 Suppl):386s-9.

39 Dewey KG, Lovelady CA, Nommsen-Rivers LA, et al. A randomized study of the effects of aerobic exercise by lactating women on breast-milk volume and composition. N Engl J Med 1994;330:449-53.

40 Lovelady CA, Lonnerdal B, Dewey KG. Lactation performance of exercising women. Am J Clin Nutr 1990;52:103-9.
41 McCrory MA, Nommsen-Rivers LA, Molé PA, et al. Randomized trial of the shortterm effects of dieting compared with dieting plus aerobic exercise on lactation performance. Am J Clin Nutr 1999;69:959-67.

42 Wallace JP, Rabin J. The concentration of lactic acid in breast milk following maximal exercise. Int J Sports Med 1991;12:328-31.

43 Groër MW, Shelton MM. Exercise is associated with elevated proinflammatory cytokines in human milk. J Obstet Gynecol Neonatal Nurs 2009;38:35-41.

44 Kovacs CS, Ralston SH. Presentation and management of osteoporosis presenting in association with pregnancy or lactation. Osteoporos Int 2015;26:2223-41.

45 Davies GA, Wolfe LA, Mottola MF, et al. Exercise in pregnancy and the postpartum period. J Obstet Gynaecol Can 2003;25:516-29.

46 ACOG Committee Opinion No. 650: physical activity and Exercise during Pregnancy and the Postpartum period. Obstet Gynecol 2015;126:e135-42.

47 Mottola MF. Exercise in the postpartum period: practical applications. Curr Sports Med Rep 2002;1:362-8.

48 McGhee DE, Steele JR, Zealey WJ, et al. Bra-breast forces generated in women with large breasts while standing and during treadmill running: implications for sports bra design. App/ Ergon 2013;44:112-8.

49 McGhee DE, Steele JR. Breast elevation and compression decrease exercise-induced breast discomfort. Med Sci Sports Exerc 2010;42:1333-8.

50 Beilock SL, Feltz DL, Pivarnik JM. Training patterns of Athletes during pregnancy and postpartum. Res Q Exerc Sport 2001;72:39-46.

51 Bo K, Backe-Hansen KL. Do elite athletes experience low back, pelvic girdle and pelvic floor complaints during and after pregnancy? Scand J Med Sci Sports 2007; 17:480-7

52 Potteiger JA, Welch JC, Byrne JC. From parturition to marathon: a 16-wk study of an elite runner. Med Sci Sports Exerc 1993;25:673-7.

53 Zaharieva E. Olympic participation by women. effects on pregnancy and childbirth. JAMA 1972;221:992-5.

54 Weina SU. Effects of pregnancy on the Army Physical Fitness Test. Mil Med 2006;171:534-7

55 Hale RW, Milne L. The elite athlete and exercise in pregnancy. Semin Perinatol 1996:20:277-84

56 Gavin NI, Gaynes BN, Lohr KN, et al. Perinatal depression: a systematic review of prevalence and incidence. Obstet Gynecol 2005;106(5 Pt 1):1071-83.

57 U.S. Department of Health and Human Services NloH. Depression. Bethesda, MD: National Institute of Mental Health, 2015.

58 Lee DT, Chung TK. Postnatal depression: an update. Best Pract Res Clin Obstet Gynaecol 2007:21:183-91.

59 Logsdon MC, Wisner KL, Pinto-Foltz MD. The impact of postpartum depression on mothering. J Obstet Gynecol Neonatal Nurs 2006;35:652-8.

60 Marcus SM. Depression during pregnancy: rates, risks and consequences--Motherisk Update 2008. Can J Clin Pharmacol 2009;16:e15-22.

61 Cooper PJ, Murray L. Course and recurrence of postnatal depression. evidence for the specificity of the diagnostic concept. Br J Psychiatry 1995;166:191-5.

62 Teychenne M, York R. Physical activity, sedentary behavior, and postnatal depressive symptoms: a review. Am J Prev Med 2013;45:217-27.

63 Songøygard KM, Stafne SN, Evensen KA, et al. Does exercise during pregnancy prevent postnatal depression? A randomized controlled trial. Acta Obstet Gynecol Scand 2012:91:62-7.

64 Horowitz JA, Bell M, Trybulski J, et al. Promoting responsiveness between mothers with depressive symptoms and their infants. J Nurs Scholarsh 2001:33:323-9.

65 Dennis CL. Can we identify mothers at risk for postpartum depression in the immediate postpartum period using the Edinburgh Postnatal Depression Scale? J Affect Disord 2004;78:163-9.

66 Daley AJ, Macarthur C, Winter $\mathrm{H}$. The role of exercise in treating postpartum depression: a review of the literature. J Midwifery Womens Health 2007;52:56-62

67 Daley A, Jolly K, MacArthur C. The effectiveness of exercise in the management of post-natal depression: systematic review and meta-analysis. Fam Pract 2009;26:154-62

68 Linné Y, Barkeling B, Rössner S. Long-term weight development after pregnancy. Obes Rev 2002;3:75-83.

69 Lim CC, Mahmood T. Obesity in pregnancy. Best Pract Res Clin Obstet Gynaecol 2015:29:309-19.

70 Olson CM, Strawderman MS, Hinton PS, et al. Gestational weight gain and postpartum behaviors associated with weight change from early pregnancy to $1 \mathrm{y}$ postpartum. Int J Obes Relat Metab Disord 2003;27:117-27.

71 Nehring I, Schmoll S, Beyerlein A, et al. Gestational weight gain and long-term postpartum weight retention: a meta-analysis. Am J Clin Nutr 2011;94:1225-31.

72 Rode L, Kjærgaard H, Ottesen B, et al. Association between gestational weight gain according to body mass index and postpartum weight in a large cohort of danish women. Matern Child Health J 2012:16:406-13.

73 Rooney BL, Schauberger CW, Mathiason MA. Impact of perinatal weight change on long-term obesity and obesity-related illnesses. Obstet Gynecol 2005;106:1349-56.

74 van der Pligt P, Willcox J, Hesketh KD, et al. Systematic review of lifestyle interventions to limit postpartum weight retention: implications for future opportunities to prevent maternal overweight and obesity following childbirth. Obes Rev 2013;14:792-805 
75 Berger AA, Peragallo-Urrutia R, Nicholson WK. Systematic review of the effect of individual and combined nutrition and exercise interventions on weight, adiposity and metabolic outcomes after delivery: evidence for developing behavioral guidelines for post-partum weight control. BMC Pregnancy Childbirth 2014;14:319.

76 Amorim Adegboye AR, Linne YM. Diet or exercise, or both, for weight reduction in women after childbirth. Cochrane Database Syst Rev 2013;7:Cd005627.

77 Nascimento SL, Pudwell J, Surita FG, et al. The effect of physical exercise strategies on weight loss in postpartum women: a systematic review and meta-analysis. Int J Obes 2014;38:626-35.

78 Wu WH, Meijer OG, Uegaki K, et al. Pregnancy-related pelvic girdle pain (PPP), I: terminology, clinical presentation, and prevalence. Eur Spine J 2004;13:575-89.

79 Bjelland EK, Stuge B, Engdahl B, et al. The effect of emotional distress on persistent pelvic girdle pain after delivery: a longitudinal population study. BJOG 2013;120:32-40.

80 Bjelland EK, Stuge B, Vangen $S$, et al. Mode of delivery and persistence of pelvic girdle syndrome 6 months postpartum. Am J Obstet Gynecol 2013;208:e1-7:298. e1-298.e7.

81 Bastiaenen $\mathrm{CH}$, de Bie RA, Vlaeyen JW, et al. Long-term effectiveness and costs of a brief self-management intervention in women with pregnancy-related low back pain after delivery. BMC Pregnancy Childbirth 2008;8:19.

82 Gutke A, Sjödahl J, Oberg B. Specific muscle stabilizing as home exercises for persistent pelvic girdle pain after pregnancy: a randomized, controlled clinical trial. $J$ Rehabil Med 2010;42:929-35.

83 Mens JM, Snijders CJ, Stam HJ. Diagonal trunk muscle exercises in peripartum pelvic pain: a randomized clinical trial. Phys Ther 2000;80:1164-73.

84 Stuge B, Laerum E, Kirkesola G, et al. The efficacy of a treatment program focusing on specific stabilizing exercises for pelvic girdle pain after pregnancy: a randomized controlled trial. Spine 2004;29:351-9.

85 Stuge B, Veierød MB, Laerum E, et al. The efficacy of a treatment program focusing on specific stabilizing exercises for pelvic girdle pain after pregnancy: a two-year follow-up of a randomized clinical trial. Spine 2004;29:E197-203.

86 Stuge B, Mørkved S, Dahl HH, et al. Abdominal and pelvic floor muscle function in women with and without long lasting pelvic girdle pain. Man Ther 2006;11:287-96

87 Liddle SD, David Baxter G, Gracey JH. Physiotherapists' use of advice and exercise for the management of chronic low back pain: a national survey. Man Ther 2009;14:189-96.

88 Smith BE, Littlewood C, May S. An update of stabilisation exercises for low back pain: a systematic review with meta-analysis. BMC Musculoskelet Disord 2014:15:416.

89 Stuge B, Garratt A, Krogstad Jenssen H, et al. The pelvic girdle questionnaire: a condition-specific instrument for assessing activity limitations and symptoms in people with pelvic girdle pain. Phys Ther 2011;91:1096-108.

90 Grotle M, Garratt AM, Krogstad Jenssen H, et al. Reliability and construct validity of self-report questionnaires for patients with pelvic girdle pain. Phys Ther 2012;92:111-23.

91 Rett M, Braga M, Bernardes N, et al. Prevalence of diastasis of the rectus abdominis muscles immediately postpartum: comparison between primiparae and multiparae. Brazilian Journal of Physical Therapy 2009;13:275-80.

92 Turan V, Colluoglu C, Turkyilmaz E, et al. Prevalence of diastasis recti abdominis in the population of young multiparous adults in Turkey. Ginekol Pol 2011;82:817-21.

93 Sperstad JB, Tennfjord MK, Hilde G, et al. Diastasis recti abdominis during pregnancy and 12 months after childbirth: prevalence, risk factors and report of lumbopelvic pain. Br J Sports Med 2016;50:1092-6.

94 Spitznagle TM, Leong FC, Van Dillen LR. Prevalence of diastasis recti abdominis in a urogynecological patient population. Int Urogynecol J Pelvic Floor Dysfunct 2007; 18:321-8.

95 Lockwood T. Rectus muscle diastasis in males: primary indication for endoscopically assisted abdominoplasty. Plast Reconstr Surg 1998;101:1685-91. discussion 92-4.

96 Gilleard WL, Brown JM. Structure and function of the abdominal muscles in primigravid subjects during pregnancy and the immediate postbirth period. Phys Ther 1996;76:750-62.

97 Liaw LJ, Hsu MJ, Liao CF, et al. The relationships between inter-recti distance measured by ultrasound imaging and abdominal muscle function in postpartum women: a 6-month follow-up study. J Orthop Sports Phys Ther 2011;41:435-43.

98 Parker MA, Millar LA, Dugan SA, et al. Diastasis Rectus Abdominis and LumboPelvic Pain and Dysfunction-Are They Related? J Womens Health Phys Therap 2009;33:15-22.

99 Fernandes da Mota PG, Pascoal AG, Carita Al, et al. Prevalence and risk factors of diastasis recti abdominis from late pregnancy to 6 months postpartum, and relationship with lumbo-pelvic pain. Man Ther 2015;20:200-5.

100 Lo T, Candido G, Janssen P. Diastasis of the recti abdominis in pregnancy: risk factors and treatment. Physiother Can 1999:51:32-6.

101 Chiarello CM, Falzone LA, McCaslin KE, et al. The effects of an exercise program on Diastasis Recti Abdominis in Pregnant Women. J Womens Health Phys Therap 2005;29:11-16.

102 Benjamin DR, van de Water AT, Peiris CL. Effects of exercise on diastasis of the rectus abdominis muscle in the antenatal and postnatal periods: a systematic review. Physiotherapy 2014;100:1-8.
103 Mesquita LA, Machado AV, Andrade AV. Physiotherapy for reduction of diastasis of the recti abdominus muscles in the post partum period. Revista Brasileira de Ginecologia e Obstetrícia 1999;21:267-72

104 Walton LM, Costa A, LaVanture D, et al. The effects of a 6 week dynamic core stability plank exercise program compared to a traditional supine core stability strengthening program on diastasis recti abdominis closure, pain, Oswestry disability index (ODI) and pelvic floor disability index scores (PFDI). Physical Therapy and Rehabilitation 2016:3:3.

105 Mota P, Pascoal AG, Carita Al, et al. The Immediate effects on Inter-rectus Distance of abdominal crunch and Drawing-in exercises during pregnancy and the Postpartum period. J Orthop Sports Phys Ther 2015;45:781-8.

106 Mota P, Pascoal AG, Sancho F, et al. Test-retest and intrarater reliability of 2-dimensional ultrasound measurements of distance between rectus abdominis in women. J Orthop Sports Phys Ther 2012;42:940-6.

107 Sancho MF, Pascoal AG, Mota P, et al. Abdominal exercises affect inter-rectus distance in postpartum women: a two-dimensional ultrasound study. Physiotherapy 2015:101:286-91.

108 Akram J, Matzen SH. Rectus abdominis diastasis. J Plast Surg Hand Surg 2014:48:163-9.

109 Emanuelsson P, Gunnarsson U, Strigård K, et al. Early complications, pain, and quality of life after reconstructive surgery for abdominal rectus muscle diastasis: a 3-month follow-up. J Plast Reconstr Aesthet Surg 2014;67:1082-8.

110 Milsom I, Coyne KS, Nicholson S, et al. Global prevalence and economic burden of urgency urinary incontinence: a systematic review. Eur Urol 2014:65:79-95.

111 Johannessen HH, Mørkved S, Stordahl A, et al. Anal incontinence and Quality of Life in late pregnancy: a cross-sectional study. BJOG 2014;121:978-87.

112 Thakar R, Stanton S. Management of genital prolapse. BMJ 2002;324:1258-62.

113 Durnea CM, Khashan AS, Kenny LC, et al. Prevalence, etiology and risk factors of pelvic organ prolapse in premenopausal primiparous women. Int Urogynecol J 2014;25:1463-70.

114 Durnea CM, O'Reilly BA, Khashan AS, et al. Status of the pelvic floor in young primiparous women. Ultrasound Obstet Gynecol 2015:46:356-62.

115 Boyle R, Hay-Smith EJ, Cody JD, et al. Pelvic floor muscle training for prevention and treatment of urinary and fecal incontinence in antenatal and postnatal women: a short version Cochrane review. Neurourol Urodyn 2014;33:269-76.

116 Dietz HP, Simpson JM. Levator trauma is associated with pelvic organ prolapse. $B J O G$ 2008:115:979-84.

117 Boyle R, Hay-Smith EJ, Cody JD, et al. Pelvic floor muscle training for prevention and treatment of urinary and faecal incontinence in antenatal and postnatal women. Cochrane Database Syst Rev 2012;10:Cd007471.

118 Hagen S, Stark D. Conservative prevention and management of pelvic organ prolapse in women. Cochrane Database Syst Rev 2011;12:Cd003882.

119 Bo K, Hilde G, Stær-Jensen J, et al. Postpartum pelvic floor muscle training and pelvic organ prolapse--a randomized trial of primiparous women. Am J Obstet Gynecol 2015;212:38.e1-38.e7.

120 Mørkved S, Bo K. The effect of postpartum pelvic floor muscle exercise in the prevention and treatment of urinary incontinence. Int Urogynecol J Pelvic Floor Dysfunct 1997:8:217-22.

121 Lipp A, Shaw C, Glavind K. Mechanical devices for urinary incontinence in women. Cochrane Database Syst Rev 2014;12:Cd001756.

122 Bugge C, Adams EJ, Gopinath D, et al. Pessaries (mechanical devices) for pelvic organ prolapse in women. Cochrane Database Syst Rev 2013;2:Cd004010.

123 Meyers WC, Kahan DM, Joseph T, et al. Current analysis of women Athletes with pelvic pain. Med Sci Sports Exerc 2011:43:1387-93.

124 Frawley H. Pelvic floor pain and the overactive pelvic floor. Evidence based Physical Therapy for the pelvic floor - bridging science and clinical practice: Elsevier 2015:333-53.

125 Abbott JA, Jarvis SK, Lyons SD, et al. Botulinum toxin type A for chronic pain and pelvic floor spasm in women: a randomized controlled trial. Obstet Gynecol 2006;108:915-23.

126 Basson R, Berman J, Burnett A, et al. Report of the international consensus development conference on female sexual dysfunction: definitions and classifications. J Uro/ 2000;163:888-93.

127 Plouffe L. Screening for sexual problems through a simple questionnaire. Am J Obstet Gynecol 1985;151:166-9.

128 Leeman LM, Rogers RG. Sex after childbirth: postpartum sexual function. Obstet Gynecol 2012;119:647-55

129 Abdool Z, Thakar R, Sultan AH. Postpartum female sexual function. Eur J Obstet Gynecol Reprod Biol 2009;145:133-7.

130 Buhling KJ, Schmidt S, Robinson JN, et al. Rate of dyspareunia after delivery in primiparae according to mode of delivery. Eur J Obstet Gynecol Reprod Biol 2006;124:42-6.

131 Andrews V, Thakar R, Sultan AH, et al. Evaluation of postpartum perineal pain and dyspareunia--a prospective study. Eur J Obstet Gynecol Reprod Biol 2008:137:152-6.

132 Klein MC, Gauthier RJ, Robbins JM, et al. Relationship of episiotomy to perineal trauma and morbidity, sexual dysfunction, and pelvic floor relaxation. Am J Obstet Gynecol 1994;171:591-8. 
133 Rowland M, Foxcroft L, Hopman WM, et al. Breastfeeding and sexuality immediately post partum. Can Fam Physician 2005;51:1366-7.

134 Khajehei M, Doherty M, Tilley PJ, et al. Prevalence and risk factors of sexual dysfunction in postpartum australian women. J Sex Med 2015;12:1415-26.

135 Barrett G, Pendry E, Peacock J, et al. Women's sexual health after childbirth. BJOG 2000;107:186-95.

136 Tennfjord MK, Hilde G, Stær-Jensen J, et al. Dyspareunia and pelvic floor muscle function before and during pregnancy and after childbirth. Int Urogynecol J 2014:25:1227-35.

137 Viswanathan M, Visco AG, Hartmann K, et al. Cesarean delivery on maternal request. Evid Rep Technol Assess 2006;133:1-138.
138 Dean N, Wilson D, Herbison P, et al. Sexual function, delivery mode history, pelvic floor muscle exercises and incontinence: a cross-sectional study six years postpartum. Aust N Z J Obstet Gynaecol 2008;48:302-11.

139 Ferreira CH, Dwyer PL, Davidson M, et al. Does pelvic floor muscle training improve female sexual function? A systematic review. Int Urogynecol J 2015;26:1735-50.

140 Ardern CL, Glasgow P, Schneiders A, et al. 2016 Consensus statement on return to sport from the First World Congress in Sports Physical Therapy, Bern. Br J Sports Med 2016;50:853-64. 